\title{
A critical appraisal of positive cooperativity in oral streptococcal adhesion: Scatchard analyses of adhesion data versus analyses of the spatial arrangement of adhering bacteria
}

\author{
Henny C. Van der Mei, ${ }^{*}$ S. Doug Cox,${ }^{2}$ Gésinda I. Geertsema-Doornbusch, ${ }^{1}$ \\ R. J. DOYlE ${ }^{2}$ and HenK J. BussCher ${ }^{1}$ \\ ${ }^{1}$ Laboratory for Materia Technica, University of Groningen, Antonius Deusinglaan 1, 9713 AV Groningen, \\ The Netherlands \\ ${ }^{2}$ Department of Microbiology, Schools of Medicine and Dentistry, University of Louisville, Louisville, \\ Kentucky 40292, USA
}

(Received 11 September 1992; revised 26 November 1992; accepted 13 January 1993)

\begin{abstract}
Positive cooperativity is a mechanism proposed to account for the adhesion of bacteria to surfaces. In this paper, two methods that both claim to assess experimentally cooperative phenomena, viz. Scatchard analysis of adhesion data (using adhesion to vials) and analysis of the spatial arrangement of adhering cells (using a flow chamber), were compared and critically evaluated. Three oral strains were used and the substrata involved were glass (hydrophilic) and silicone-coated glass (hydrophobic) employed with or without a salivary coating. Scatchard analysis and nearneighbour analysis of adhering cells yield similar conclusions with regard to the mechanism of adhesion of the cells, provided that adhering cells are sufficiently immobilized under the experimental conditions. In the case of incomplete immobilization, near-neighbour collection results from sliding of adhering cells rather than from cooperative phenomena. Also, the agreement between the conclusions from both methods seems to be better, the more reversibly the cells adhere. Positive cooperativity can be absent or present on saliva-coated substrata with a distinct effect of the substratum hydrophobicity, despite the presence of an adsorbed film. This suggests that a different pellicle develops on a hydrophobic substratum than on a hydrophilic substratum. This is confirmed by our observation that the amino acid composition of salivary films is different on both types of substratum.
\end{abstract}

\section{Introduction}

Positive cooperativity is a mechanism which microorganisms can utilize to colonize a surface. Doyle et al. (1982), hypothesizing on the mechanism of adhesion of Streptococcus sanguis to saliva-coated hydroxylapatite, described positive cooperativity as the capacity of initially bound cells to change the available substratum surface in their immediate surroundings, thereby creating new receptor sites for other cells. Hitherto, the evidence for the existence of positive cooperativity has been indirect and subject to debate. Most often a Scatchard analysis is made of the adhesion data according to:

$$
\frac{B}{U}=K(N-B)
$$

\footnotetext{
*Author for correspondence. Tel. 3150 633124; fax 3150633159 .
}

in which $B$ is the number of bound cells, $U$ is the number of unbound cells, $K$ is the affinity constant and $N$ the number of available sites on the substratum surface. Provided $N$ is a constant, a plot of $B / U$ versus $B$ should have a negative slope. However, if $N$ increases due to the presence of initially bound cells, creating new binding sites, i.e. positive cooperativity, then positive slopes arise in the Scatchard plot. Since the introduction of the concept of positive cooperativity, cooperative phenomena have been described or deduced for a number of bacteria including Actinomyces viscosus to saliva-coated hydroxylapatite, Chlamydia trachomatis to HeLa cells, Escherichia coli to BHK tissue culture cells, Haemophilus parainfluenzae to saliva-coated hydroxylapatite, Lactobacillus casei and E. coli to uroepithelial cells, Pseudomonas fuorescens to glass and $S$. sanguis to salivacoated hydroxylapatite (reviewed by Doyle, 1991).

Whereas there is no debate about the existence of positive cooperativity as such, its derivation from a 
Scatchard analysis of adhesion data needs support. The Scatchard analysis is a linearization scheme of the Langmuir equation:

$$
\frac{U}{B}=\frac{1}{K N}+\frac{U}{N}
$$

The Langmuir equation, however, and therefore also the Scatchard linearization, was originally derived for the adsorption of gas molecules on surfaces and involves several assumptions:

(i) only monolayer adsorption occurs,

(ii) there is a finite number of identical binding sites per unit area,

(iii) the interacting species must approach without steric hindrance,

(iv) measurements are taken at equilibrium, and

(v) adsorption is completely reversible.

Clearly, these assumptions are not always met for microbial adhesion, which is the reason that Scatchard analysis requires independent verification.

Recently, Sjollema et al. $(1990 a, b)$ have described a completely different approach to assess cooperative phenomena in microbial adhesion, based on the realization that, in the case of positive cooperativity, adhering cells should show a preference for adhesion in the neighbourhood of each other. The approach described analyses the spatial arrangement of adhering cells on a surface by radial and angular distribution functions, which denote the local relative density of adhering cells. Positive cooperativity is then concluded from high local relative densities around a given adhering cell (Sjollema et al., $1990 a, b$ ). Analyses of the spatial arrangements of adhering cells can only be done, however, when it is ascertained that the spatial arrangement to be analysed is exactly the one as existing during the experiment (Busscher et al., 1990). One passage of a substratum with adhering cells through a liquid-air interface or any 'slight rinsing' procedure can dramatically alter the spatial arrangement of adhering cells. This approach can therefore only be taken when using flow chamber systems with in situ observations.

Neither the work done with Scatchard analysis, nor the work based on analysis of the spatial arrangement of adhering cells has yielded a clear indication of the factors influencing positive cooperativity. Positive cooperativity on saliva-coated substrata has been explained predominantly by the capacity of adhering cells to induce conformational changes in the pellicle or on the surfaces of approaching cells, thereby creating new receptor sites for adhesion (Doyle et al., 1982).

Yet, positive cooperative phenomena have also been described for oral streptococci adhering to inert substrata such as glass and Teflon (Busscher et al., 1990). Proposed explanations are based on the relative magnitude of the interaction forces between adhering cells and their substrata as compared with the interaction forces between adhering cells. The presence of surface appendages has been mentioned as one of the prerequisites for cells to express positive cooperativity (Sjollema et al. $1990 a, b$ ).

The aim of this paper is to determine whether Scatchard analysis of microbial adhesion data yields the same conclusions about cooperative mechanisms as does an analysis of the spatial arrangement of adhering cells. To this end, experiments have been done on adhesion of three oral microbial strains to a hydrophilic (glass) and a hydrophobic (silicone-coated glass) substratum in the absence and presence of a salivary coating. Data to be employed in the Scatchard analysis were obtained in a test tube with radioactively labelled cells, whereas the spatial arrangement of adhering cells was examined making use of a parallel plate flow chamber with in situ observation and unlabelled cells.

\section{Methods}

Bacterial strains, growth conditions and cell surface characteristics. The oral bacteria Streptococcus sanguis ATCC 10556, S. salivarius HB and a mutant strain of $S$. salivarius $\mathrm{HB}, \mathrm{HBC12}$, were used in this study. Cells were grown in $5 \%(\mathrm{v} / \mathrm{v}) \mathrm{CO}_{2}$ at $37^{\circ} \mathrm{C}$ from a frozen stock, in batch culture in Todd-Hewitt broth. This culture was used to inoculate a second culture, which was grown for $16 \mathrm{~h}$ and then harvested by centrifugation and washed twice with a high or low ionic strength $\mathrm{KCl}$ buffer $(2 \mathrm{~mm}$-potassium phosphate and $1 \mathrm{~mm}$-calcium chloride, with $50 \mathrm{~mm}$-potassium chloride for the low and $500 \mathrm{~mm}$ potassium chloride for the high ionic strength buffer, $\mathrm{pH} 6 \cdot 8$ ).

Flow chamber adhesion experiments were done with cells grown as described above. However, adhesion experiments to the glass vials were done with radiolabelled cells. The bacteria were radiolabelled by growing them in the broth medium supplemented with $10 \mu \mathrm{Ci}$ $(0.37 \mathrm{MBq})\left[{ }^{3} \mathrm{H}\right]$ thymidine $\mathrm{mi}^{-1}$. For flow chamber adhesion experiments, bacterial chains were broken by slight sonication for $15 \mathrm{~s}$. Subsequently, the cell pellets were resuspended in $\mathrm{KCl}$ buffer to a cell density of $3 \times 10^{8}$ bacteria $\mathrm{ml}^{-1}$ (or as otherwise stated) for the flow chamber experiments; for adhesion experiments in glass vials, a population density range of $4 \times 10^{6}-6 \times 10^{9}$ bacteria $\mathrm{ml}^{-1}$ was prepared.

Table 1 summarizes the surface characteristics relevant for adhesion of the strains employed. Estimated bacterial diameters are given as they

\section{Table 1. Surface characteristics of the three oral streptococcal strains used in this study}

Water contact angles $\left(\theta_{\mathrm{H}_{2} \mathrm{O}}\right)$ and microbial adhesion to hexadecane (Hex) were employed as a measure of hydrophobicity. The zeta potential $(\zeta)$ in low ionic strength $\mathrm{KCl}$ buffer was used as a measure of surface charge [for a description of the techniques used, see James (1991) and Van der Mei et al. (1991)]. Bacterial diameters $(d)$ were estimated by phase-contrast microscopy.

\begin{tabular}{lcccc}
\hline \hline Strain & $\theta_{\mathrm{H}_{2} \mathrm{O}}\left({ }^{\circ}\right)$ & $\mathrm{Hex}(\%)$ & $\zeta(\mathrm{mV})$ & $d(\mu \mathrm{m})$ \\
\hline S. salivarius HB & 59 & 41 & -13 & $1 \cdot 1$ \\
S. salivarius HBC12 & 21 & 5 & -9 & $1 \cdot 1$ \\
S. sanguis ATCC 10556 & 42 & 11 & -7 & $1 \cdot 0$ \\
\hline \hline
\end{tabular}



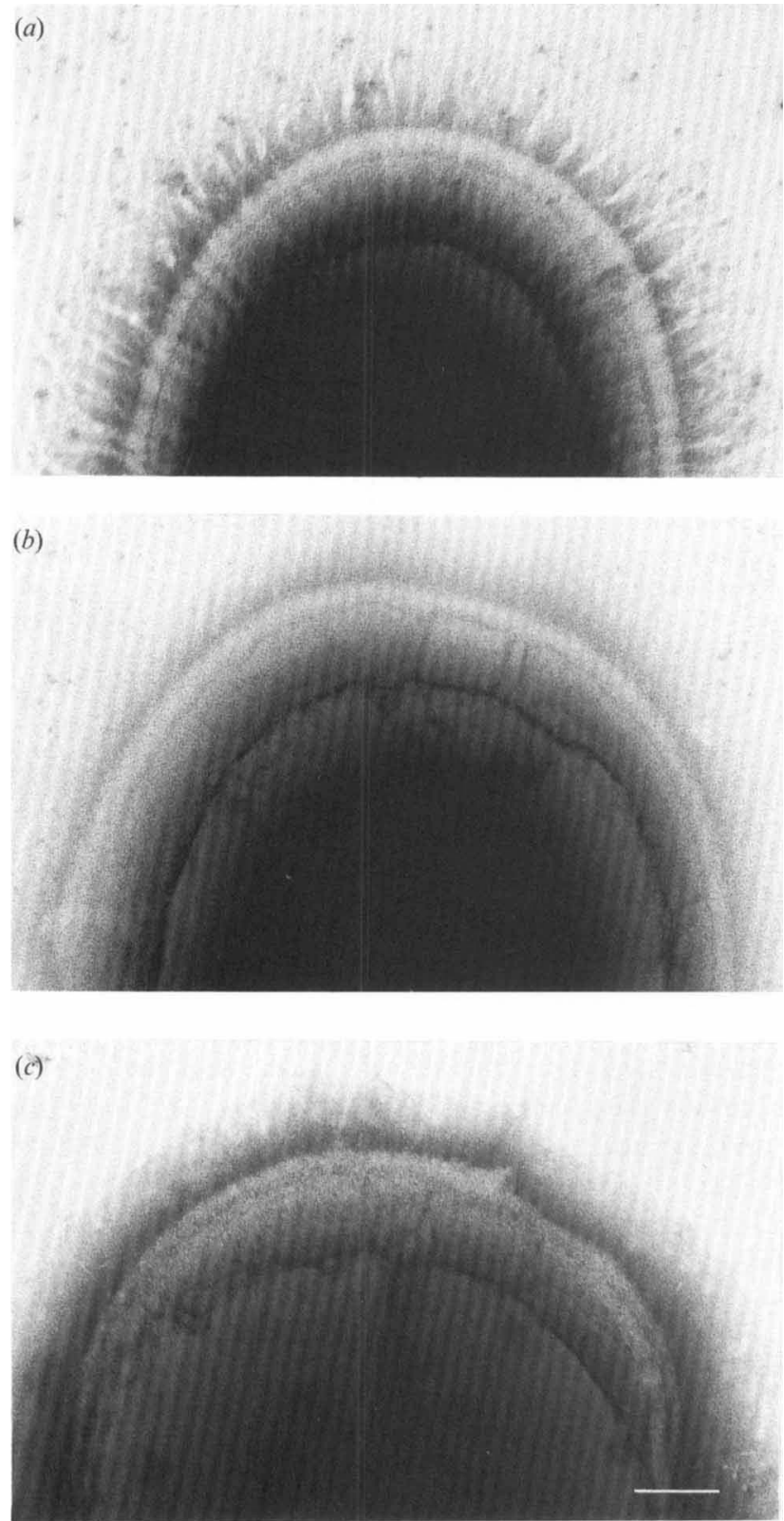

Fig. 1. Transmission electron micrographs of negatively stained (methylaminetungstate) cells of $(a) S$. salivarius $\mathrm{HB},(b) S$. salivarius $\mathrm{HBC} 12$ and $(c) S$. sanguis ATCC 10556. Bar, $100 \mathrm{~nm}$.

are required to interpret the deposition kinetics. In addition, Fig. 1 presents transmission electron micrographs of cells negatively stained with $1 \%(\mathrm{w} / \mathrm{v})$ methylamine tungstate to demonstrate structural differences between the cell surfaces of the strains.

Saliva. Human whole saliva was collected into ice-chilled cups from 10 healthy volunteers of both sexes after stimulation by chewing Parafilm. After pooling, the saliva was centrifuged at $10000 \mathrm{~g}$ for $20 \mathrm{~min}$ at $4{ }^{\circ} \mathrm{C}$. Subsequently, PMSF was added to a final concentration of $1 \mathrm{mM}$ as a protease inhibitor. Then the solution was again centrifuged, dialysed overnight at $4{ }^{\circ} \mathrm{C}$ against demineralized water and finally freeze-dried for storage. Reconstituted, human whole saliva was prepared by dissolving the freeze-dried stock to a concentration of $1.5 \mathrm{mg} \mathrm{ml}^{-1}$ in low ionic strength $\mathrm{KCl}$ buffer.

Substrata. For adhesion experiments, glass vials were used as received from the manufacturer. To make them hydrophobic they were coated with silicone (Sigmacote, Sigma). The vials were filled with Sigmacote and after $30 \mathrm{~s}$ emptied and air-dried. For flow chamber adhesion experiments, $2.0 \mathrm{~mm}$ thick glass plates $(7.5 \times 5.0 \mathrm{~cm})$ were thoroughly cleaned by sonication in a detergent solution $[2 \%, \mathrm{v} / \mathrm{v}$, RBS (Chemical Products) in demineralized water], extensive rinsing in demineralized water, washing in methanol and again rinsing in demineralized water. This procedure yielded a water contact angle of $0^{\circ}$.

To create a hydrophobic surface these cleaned glass plates were also coated with Sigmacote, rinsed thoroughly with demineralized water and dried overnight in an oven at $80^{\circ} \mathrm{C}$. This procedure yielded a water contact angle of $91^{\circ}$

Assay of adhesion to vials. A radiolabelled bacterial suspension $(1.5 \mathrm{ml})$ in $\mathrm{KCl}$ buffer was added to a glass vial and rotated (12 r.p.m.) for $1.5 \mathrm{~h}$. A series of 10 dilutions of the cell suspension was used, with densities varying between $4 \times 10^{6}$ and $6 \times 10^{9}$ cells ml$^{-1}$. After the adhesion period, the vial was emptied and $100 \mu \mathrm{l}$ of the radiolabelled bacterial suspension was saved for quantification of unbound cells. The vial was then washed three times with buffer and $7 \mathrm{ml}$ scintillation cocktail was added to both the glass vial and the extra vial containing $100 \mu \mathrm{l}$ of the unbound cell suspension. The radioactivity in each vial was counted in a scintillation spectrometer to yield both $B$ and $U$. In addition to glass vials, silicone-coated and saliva-coated vials were also used. For saliva coating, $1.5 \mathrm{ml}$ saliva was added to the glass vial or silicone-coated glass vial which were then rotated for $1.5 \mathrm{~h}$ and washed three times with buffer (low or high ionic strength) before the adhesion assay was initiated. All adhesion experiments were done in triplicate with three separate bacterial cultures.

Data obtained using the vials were subjected to Scatchard analysis according to eqn (1). The occurrence of a positive slope was taken as evidence of positive cooperativity. Only when at least two independent experimental runs indicated positive cooperativity, were results considered decisive.

Flow chamber adhesion. Deposition was directly observed in situ on the glass bottom and $7 \mathrm{~cm}$ from the inlet of a parallel plate flow chamber $(5 \times 16 \mathrm{~cm})$ with a channel height of $0.06 \mathrm{~cm}$. By means of a valve system (Pratt-Terpstra et al., 1987) the chamber was connected to flasks containing either buffer, reconstituted human whole saliva or bacterial suspension.

The number of deposited bacteria was observed with a ccd-MX camera (High Technology) mounted on a phase-contrast microscope (Olympus BH-2) equipped with a $40 \times$ ultra-long working distance objective (Olympus ULWD-CD Plan 40 PI). The camera was coupled to an image analyser (TEA, Difa).

Prior to each experiment all tubes and the flow chamber were filled with buffer, care being taken to remove air bubbles from the system. Flasks, containing bacterial suspension, buffer and reconstituted human whole saliva when appropriate, were positioned at the same height with respect to the chamber, so that immediately after switching flows, all fluids would circulate through the chamber under the influence of hydrostatic pressure at the desired shear rate of $16 \mathrm{~s}^{-1}$ $\left(0.036 \mathrm{ml} \mathrm{s}^{-1}\right)$, which corresponds to physiological conditions of moderate shear (Dawes et al., 1989; Vissink et al., 1984) and yields a laminar flow (Reynolds number of $0 \cdot 9$ ). First, flow was switched to saliva, if appropriate, for $1.5 \mathrm{~h}$ in order to create a salivary coating. Thereafter, flow was switched for $1 \mathrm{~h}$ to buffer to remove all remnants of saliva from the tubes and chamber, and subsequently to the bacterial suspension. The bacterial suspension was circulated through the system for $4-5 \mathrm{~h}$, and images were obtained at the highest possible rate. 
Bacteria were enumerated immediately by computer, as described elsewhere. The time interval between two images varied from $2 \mathrm{~min}$ in the beginning to $10 \mathrm{~min}$ in the later stages of the experiment, depending on the number of adhering cells. During the course of an experiment, four images were stored for examination of desorption phenomena: two were taken approximately $1000 \mathrm{~s}$ and two others approximately $5000 \mathrm{~s}$ after the start of the experiment. The microscope was focused on one part of the substratum, located in the centre of the chamber during the entire experiment. When adhesion had reached a stationary state, however, additional images of other parts around the centre of the chamber were grabbed and stored. This procedure generally yielded a number of stored images containing a total of 2000-3000 adhering cells for analysis of near-neighbour collection. Finally, while remaining focused on a particular part of the substratum, the number of adhering cells was enumerated in this field of view and flow was switched to buffer to remove non-adhering cells from the tubes and chamber. The chamber was then emptied by hydrostatic pressure to permit a liquid-air interface to pass gently over the adhering cells and the number of cells retained was counted. This simple, additional experiment was routinely done to determine the percentage of cells removed upon draining the chamber, i.e. to estimate the errors involved in studies applying 'slight rinsing' and the retention capacities of the strains. All experiments were done in triplicate with separate bacterial cultures at room temperature.

After automated enumeration of the numbers of adhering cells in the images, data were transformed to cells adhering per unit area and leastsquare fitted to (Dabros \& Van de Ven, 1982):

$$
n_{\mathrm{b}}(t)=n_{\mathrm{s}}\left(1-\mathrm{e}^{-\beta_{0} \cdot}\right)
$$

in which $n_{\mathrm{b}}$ is the number of cells adhering per unit area at time $t, n_{\mathrm{s}}$ is the number of cells adhering per unit area in a stationary state and $\beta_{0}$ describes the way in which the adhesion process approaches a stationary state and includes blocking, desorption and effects of biosurfactant production by the adhering cells. The initial deposition rate, $j_{0}$ can be derived from $n_{\mathrm{s}}$ and $\beta_{0}$ according to:

$$
j_{0}=n_{\mathrm{s}} \cdot \beta_{0}
$$

Desorption of adhering cells during the course of a deposition experiment was assessed from the two successively stored images by counting the number of cells $\Delta n_{21}$ that desorbed during the time interval between successively stored images. A reciprocal desorption time constant, $\alpha$, with the same dimensions as $\beta_{0}$ in eqn (3), can then be calculated according to:

$$
\alpha=\frac{\Delta n_{21}}{n_{\mathrm{b}}\left(t_{1}\right) \cdot\left(t_{2}-t_{1}\right)}
$$

in which $t_{2}$ and $t_{1}$ represent the times at which the images to be compared were stored. Desorption by comparison of two images was assessed approximately $1000 \mathrm{~s}$ and $5000 \mathrm{~s}$ after the start of an experiment.

The spatial arrangement of the adhering cells was analysed from the images stored at the end of each experiment. Taking each of the 2000-3000 adhering particles as centre points, local densities of adhering cells were determined in a shell with thickness $d r$ at a distance $r$ from the centre point and in segments of this shell at an angle $\theta$ with respect to the direction of flow and with angular width $d \theta$. These local densities, referred to as $\rho(r, d r)$ and $\rho(r, d r, \theta, d \theta)$, respectively, were normalized with respect to the average density $\rho_{0}$ of adhering cells, yielding a radial distribution function:

$$
g(r)=\frac{\rho(r, d r)}{\rho_{0}}
$$

and an angular distribution function:

$$
g(\theta)=\frac{\rho(r, d r, \theta, d \theta)}{\rho_{0}}
$$

Details about the exact calculation of these distribution functions have been given elsewhere (Sjollema \& Busscher, 1990; Sjollema et al., $1990 b$ ).

$P A G E$ of adsorbed saliva. Vials (glass or silicone-coated glass) containing a solution of $1.5 \mathrm{mg}$ saliva $\mathrm{ml}^{-1}$ in low or high ionic strength buffers (see Table 2) were rotated for $90 \mathrm{~min}$ at room temperature. The vials were then decanted and rinsed twice with the respective buffers and drained dry. Adherent protein was solubilized by the SDS-2mercaptoethanol buffer of Laemmli (1970). The protein solutions were then applied to polyacrylamide gels for electrophoresis.

Amino acid analysis of adsorbed salivary films. Salivary films, prepared as described above, were solubilized with $6 \mathrm{M}$-hydrochloric acid and then hydrolysed for $21 \mathrm{~h}$ at $110^{\circ} \mathrm{C}$ in vacuo. The hydrolysates were dried in vacuo and mixed with fresh derivatization reagent [ethanol/water/triethylamine/phenylisothiocyanate, $7: 1: 1: 1$ by vol. (Tweedie et al., 1991)]. The samples were then evaporated to dryness and taken up in 5 mM-sodium phosphate $(\mathrm{pH} \mathrm{7.4)}$ containing $5 \%(\mathrm{v} / \mathrm{v})$ acetonitrile. Samples were then analysed on a Waters Pico Tag system amino acid analyser, employing an acetonitrile gradient.

\section{Results}

\section{Scatchard analyses of streptococcal adhesion to vials}

Fig. 2 shows examples of two Scatchard plots of the adhesion data representing positive cooperativity and non-cooperativity. Table 2 summarizes the outcome of the Scatchard analysis of the adhesion data. Only in $10 \%$ of all strain/substratum combinations did one of the three experimental runs carried out give an aberrant result compared to the other two runs. S. salivarius

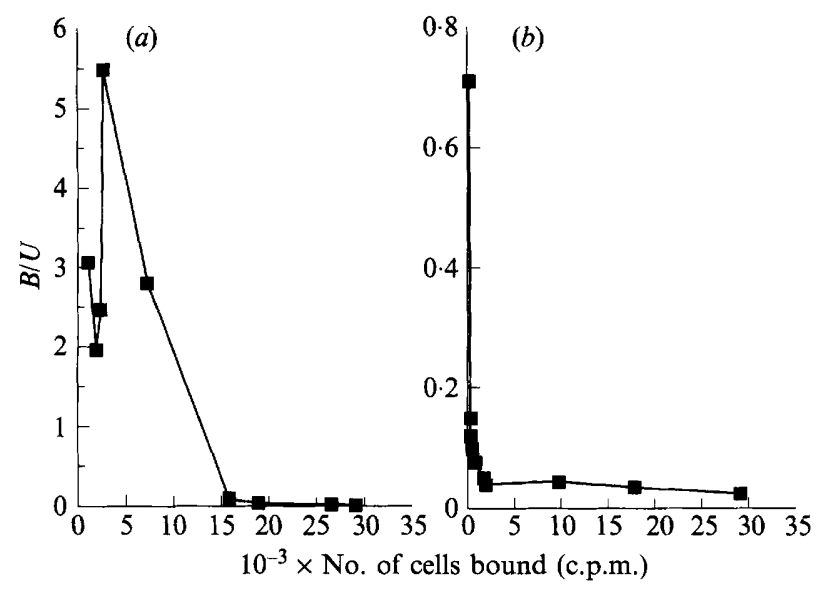

Fig. 2. Examples of Scatchard analysis of $S$. salivarius HB adhesion data to glass with ( $a$, demonstrating positive cooperativity) and without ( $b$, demonstrating non-cooperativity) a salivary coating in low ionic strength buffer. 
Table 2. Summary of non-cooperativity $(N C)$ and positive cooperativity $(C)$ in the adhesion of oral streptococci to glass without $(G)$ and with $\left(G^{+}\right)$a salivary coating, and to silicone-coated glass without $(S G)$ and with $\left(S G^{+}\right)$a salivary coating, as revealed by Scatchard analyses of adhesion data

All experiments were done in triplicate with three separate bacterial cultures.

\begin{tabular}{lcrrr}
\hline \hline Strain & $\mathrm{G}$ & $\mathrm{G}^{+}$ & $\mathrm{SG}$ & $\mathrm{SG}^{+}$ \\
\hline $\begin{array}{l}\text { S. salivarius } \mathrm{HB} \\
\text { Buffer 1* }\end{array}$ & $\mathrm{NC}$ & $\mathrm{C}$ & $\mathrm{C}$ & $\mathrm{C}$ \\
$\quad$ Buffer 2 \\
$\begin{array}{l}\text { S. salivarius } \mathrm{HBC12} \\
\quad \text { Buffer 1 }\end{array}$ & $\mathrm{NC}$ & $\mathrm{C}$ & $\mathrm{C}$ & $\mathrm{NC}$ \\
$\quad$ Buffer 2 & $\mathrm{NC}$ & $\mathrm{NC}$ & $\mathrm{NC}$ & $\mathrm{NC}$ \\
S. Sanguis ATCC 10556 & $\mathrm{NC}$ & $\mathrm{NC}$ & $\mathrm{NC}$ & $\mathrm{NC}$ \\
Buffer 1 & & & & \\
Buffer 2 & $\mathrm{NC}$ & $\mathrm{C}$ & $\mathrm{C}$ & $\mathrm{NC}$ \\
\hline \hline
\end{tabular}

* Buffer 1, 2 mM-potassium phosphate, $50 \mathrm{~mm}-\mathrm{KCl}, 1 \mathrm{~mm}-\mathrm{CaCl}_{2}$. $\dagger$ Buffer 2, 2 mM-potassium phosphate, $500 \mathrm{~mm}-\mathrm{KCl}, 1 \mathrm{~mm}-\mathrm{CaCl}_{2}$.

HBC12, the bald mutant of $S$. salivarius $\mathrm{HB}$, adheres non-cooperatively in both buffers to both substrata irrespective of the presence of a salivary film. In contrast, S. salivarius HB and S. sanguis ATCC 10556 adhere noncooperatively to glass but cooperatively to silicone-coated glass in both buffers. The mechanism of adhesion of $S$. sanguis ATCC 10556 to saliva-coated glass and $S$. salivarius HB to saliva-coated siliconized glass appears to be influenced by the ionic strength of the buffer.

\section{Analysis of flow chamber adhesion}

Flow chamber adhesion studies could only be done in low ionic strength buffer because shear-induced aggregation of cells (i.e. aggregation of cells due to the fluid flow in the tubing and flow chamber itself) in suspension

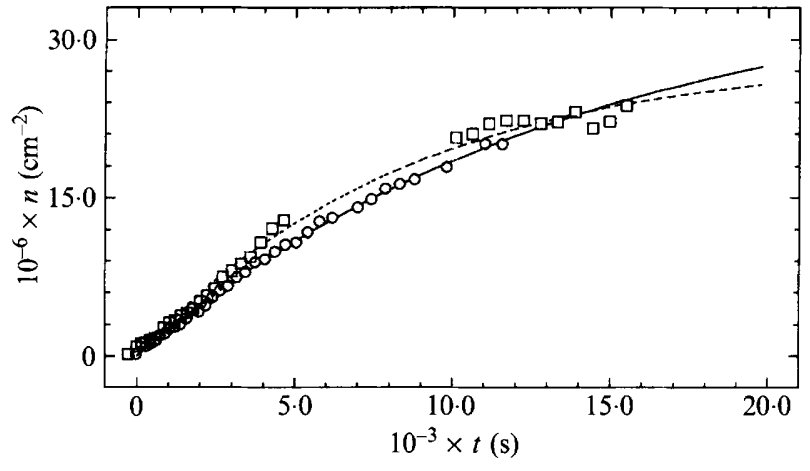

Fig. 3. Examples of the deposition kinetics of $S$. salivarius $\mathrm{HB}$ to glass with $(\square)$ and without $(O)$ a salivary coating. The drawn lines represent the fit of the data points to eqn (3).

occurred in high ionic strength buffer. Fig. 3 illustrates an example of the deposition kinetics observed for $S$. salivarius $\mathrm{HB}$ on glass with and without a salivary coating. Table 3 presents the quantitative data calculated from such curves for all the bacteria and substrata studied. The initial deposition rate, $j_{0}$, appears straindependent, but also variable with substratum and influenced by the presence of a salivary coating. Note that $j_{0}$ has no relation with the number of cells adhering in the stationary state, $n_{s}$, when comparing different substrata, due to differences in the characteristic time dependence of the adhesion process on the various substrata. Table 4 presents data showing the reversibility of adhesion and the retention capacity of the strains to the different substrata. The desorption rate, $\alpha$, shows on average a tenfold lower desorption rate upon a fivefold increase in the contact time for all substrata. The desorption rate for $S$. salivarius $\mathrm{HBC} 12$ to bare substrata is very high, corresponding to the high percentage removed upon draining the flow chamber, although in general 'reversibility' and 'retention' as implied in this study do not necessarily have to be related. All bacteria

Table 3. Analysis of the deposition kinetics of the oral streptococci tested to glass without $(G)$ and with $\left(G^{+}\right)$a salivary coating, and to silicone-coated glass without $(S G)$ and with $\left(S G^{+}\right)$a salivary coating, in low ionic strength buffer

All data represent averages of three experiments with separate bacterial cultures, yielding average SD values of $\pm 30 \%$, $\pm 70 \%$ and $\pm 40 \%$ of the mean for $j_{0}, \beta_{0}$ and $n_{\mathrm{s}}$, respectively.

\begin{tabular}{|c|c|c|c|c|c|c|c|c|c|c|c|c|}
\hline \multirow[b]{2}{*}{ Strain } & \multicolumn{4}{|c|}{$j_{0}\left(\mathrm{~cm}^{-2} \mathrm{~s}^{-1}\right)$} & \multicolumn{4}{|c|}{$\beta_{0}\left(\times 10^{-5} \mathrm{~s}^{-1}\right)$} & \multicolumn{4}{|c|}{$n_{\mathrm{s}}\left(\times 10^{6} \mathrm{~cm}^{-2}\right)$} \\
\hline & $\mathrm{G}$ & $\mathrm{G}^{+}$ & SG & $\mathrm{SG}^{+}$ & G & $\mathrm{G}^{+}$ & SG & $\mathrm{SG}^{+}$ & $\mathrm{G}$ & $\mathrm{G}^{+}$ & SG & $\mathrm{SG}^{+}$ \\
\hline S. salivarius $\mathrm{HB}$ & 2712 & 3263 & 2167 & 2607 & 8.4 & $11 \cdot 3$ & 6.5 & $8 \cdot 2$ & 39 & 30 & 37 & 34 \\
\hline S. salivarius $\mathrm{HBC} 12$ & 1990 & -* $^{*}$ & 3458 & - & 173 & - & 205 & - & 1.4 & - & $2 \cdot 1$ & - \\
\hline S. sanguis ATCC 10556 & 2489 & 2535 & 2497 & 1593 & 8.9 & $11 \cdot 1$ & $22 \cdot 6$ & $4 \cdot 2$ & 30 & 27 & 13 & 39 \\
\hline
\end{tabular}

*-denotes that the number of adhering cells in the field of view $\left(0.016 \mathrm{~mm}^{2}\right)$ was too low $\left(<0.1 \times 10^{6} \mathrm{~cm}^{-2}\right)$ for accurate analysis. 
Table 4. The reversibility of adhesion and the retention capacity of the oral streptococci tested expressed as the desorption time constant, $\alpha$, determined approximately $1000 \mathrm{~s}$ and $5000 \mathrm{~s}$ after the onset of an experiment, and expressed as the percentage cells removed upon draining the flow chamber after the experiment

Substrata used were glass without $(\mathrm{G})$ and with $\left(\mathrm{G}^{+}\right)$a salivary coating, and silicone-coated glass without (SG) and with $\left(\mathrm{SG}^{+}\right)$a salivary coating. These experiments were done in low ionic strength buffer. Data represent the average of three experiments with separate bacterial cultures, yielding an average SD value of $40 \%$ of the mean. ND, Not determined.

\begin{tabular}{|c|c|c|c|c|c|c|c|c|}
\hline \multirow[b]{3}{*}{ Strain } & \multicolumn{8}{|c|}{$\alpha\left(\times 10^{-5} \mathrm{~s}^{-1}\right)$} \\
\hline & \multicolumn{2}{|c|}{$\mathrm{G}$} & \multicolumn{2}{|c|}{$\mathrm{G}^{+}$} & \multicolumn{2}{|c|}{ SG } & \multicolumn{2}{|c|}{$\mathrm{SG}^{+}$} \\
\hline & $1000 \mathrm{~s}$ & $5000 \mathrm{~s}$ & $1000 \mathrm{~s}$ & $5000 \mathrm{~s}$ & $1000 \mathrm{~s}$ & $5000 \mathrm{~s}$ & $1000 \mathrm{~s}$ & $5000 \mathrm{~s}$ \\
\hline S. salivarius HB & $3 \cdot 5$ & $0 \cdot 2$ & $3 \cdot 2$ & $0 \cdot 1$ & 15 & 0.4 & 11 & $0 \cdot 2$ \\
\hline S. salivarius $\mathrm{HBC} 12$ & 33 & $4 \cdot 7$ & ND & ND & 33 & $5 \cdot 2$ & ND & ND \\
\hline \multirow[t]{3}{*}{ S. sanguis ATCC 10556} & $3 \cdot 0$ & $0 \cdot 1$ & $6 \cdot 2$ & $0 \cdot 2$ & $3 \cdot 8$ & $0 \cdot 3$ & $4 \cdot 3$ & $0 \cdot 4$ \\
\hline & \multicolumn{8}{|c|}{ Percentage cells removed } \\
\hline & \multicolumn{2}{|c|}{ G } & \multicolumn{2}{|c|}{$\mathrm{G}^{+}$} & \multicolumn{2}{|c|}{ SG } & \multicolumn{2}{|c|}{$\mathrm{SG}^{+}$} \\
\hline S. salivarius $\mathrm{HB}$ & & 4 & & 0 & & 12 & & 60 \\
\hline S. salivarius $\mathrm{HBC} 12$ & & 44 & & ND & & 96 & & ND \\
\hline S. sanguis ATCC 10556 & & 25 & & 37 & & 30 & & 43 \\
\hline
\end{tabular}

(a)

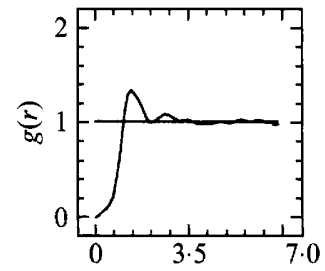

(b)

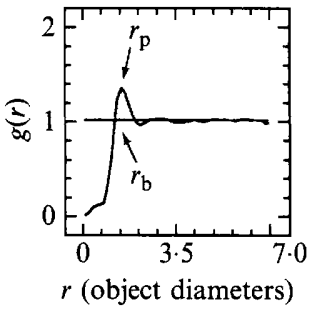

(Near)
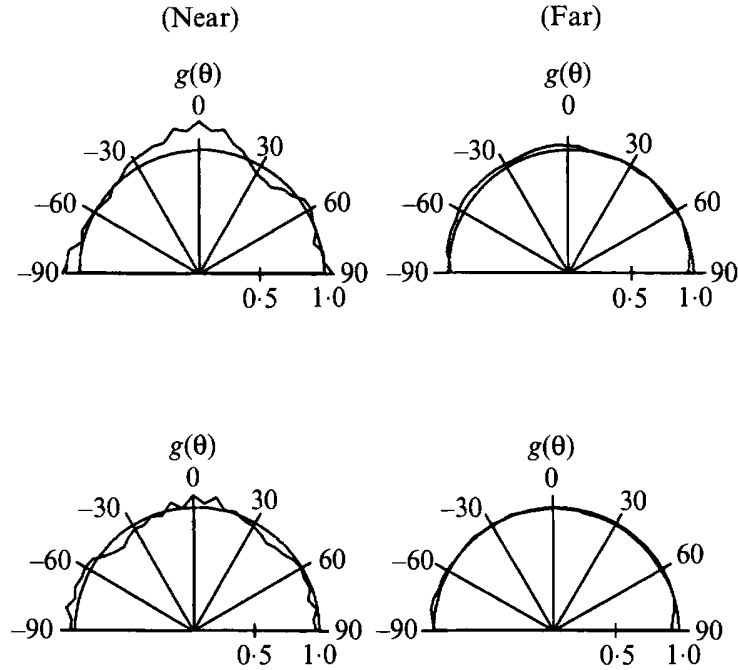

Fig. 4. Examples of radial and angular distribution functions of $S$. salivarius $\mathrm{HB}$ to glass with $(a)$ and without $(b)$ a salivary coating. Note that for $r<r_{\mathrm{b}}$ (the so-called 'blocking distance'), relative local densities are smaller $[g(r)<1]$ than average, whereas at $r=r_{\mathrm{p}}$ (the 'preferential adhesion distance'), local densities are maximal. $\lim _{r \rightarrow \infty} g(r)=1$, because the area of such a shell goes to infinity and its local density is exactly average. The angular distribution functions are presented both for 'near' and 'far' neighbours.

demonstrated a lower retention capacity on a hydrophobic substratum than on a hydrophilic substratum.

Examples of radial and angular distribution functions are given in Fig. 4, and their quantitative features are summarized in Tables 5 and 6 , respectively. For $S$. salivarius $\mathrm{HB}$ the blocking distance, $r_{\mathrm{b}}$, the distance of preferential adhesion, $r_{\mathrm{p}}$, as well as the relative local density, $g\left(r_{\mathrm{p}}\right)$, are independent of substratum hydrophobicity and the absence or presence of a salivary coating. The blocking distance for $S$. salivarius $\mathrm{HBC} 12$ is minimal, i.e. one bacterial diameter, whereas $S$. sanguis has the largest blocking area. The $g\left(r_{\mathrm{p}}\right)$ values range from 
Table 5. Characteristics of the radial distribution functions of the oral streptococci tested adhering to glass without $(G)$ and with $\left(G^{+}\right)$a salivary coating and to silicone-coated glass without $(S G)$ and with $\left(S G^{+}\right)$a salivary coating

Data represent the average of three experiments with separate bacterial cultures; the SD was $0 \cdot 1$ bacterial diameter for $r_{\mathrm{b}}$ and $r_{\mathrm{p}}$, and $0 \cdot 1$ for $g\left(r_{\mathrm{p}}\right)$.

\begin{tabular}{|c|c|c|c|c|c|c|c|c|c|c|c|c|}
\hline \multirow[b]{2}{*}{ Strain } & \multicolumn{4}{|c|}{$r_{\mathrm{b}}$ (bacterial diameters) } & \multicolumn{4}{|c|}{$r_{\mathrm{p}}$ (bacterial diameters) } & \multicolumn{4}{|c|}{$g\left(r_{\mathrm{p}}\right)$} \\
\hline & G & $\mathrm{G}^{+}$ & SG & $\mathrm{SG}^{+}$ & $\mathrm{G}$ & $\mathrm{G}^{+}$ & SG & $\mathrm{SG}^{+}$ & G & $\mathrm{G}^{+}$ & SG & $\mathrm{SG}^{+}$ \\
\hline S. salivarius $\mathrm{HB}$ & $1 \cdot 3$ & $1 \cdot 3$ & $1 \cdot 3$ & 1.4 & 1.6 & $1 \cdot 7$ & $1 \cdot 6$ & 1.7 & $1 \cdot 3$ & $1 \cdot 3$ & $1 \cdot 3$ & $1 \cdot 3$ \\
\hline S. salivarius $\mathrm{HBC} 12$ & $1 \cdot 0$ & $-*$ & $1 \cdot 0$ & - & $1 \cdot 2$ & - & 1.5 & - & 1.5 & - & $1 \cdot 7$ & - \\
\hline S. sanguis ATCC 10556 & 1.5 & 1.4 & $1 \cdot 7$ & $1 \cdot 4$ & $1 \cdot 7$ & $1 \cdot 6$ & 1.9 & 1.8 & $1 \cdot 2$ & $1 \cdot 4$ & $1 \cdot 1$ & $1 \cdot 2$ \\
\hline
\end{tabular}

${ }^{*}$ - indicates that the number of $S$. salivarius $\mathrm{HBC} 12$ cells per image was too small to enable calculation of distribution functions.

Table 6. Characteristics of the angular distribution functions of the oral streptococci tested adhering to glass without $(G)$ and with $\left(G^{+}\right)$a salivary coating, and to silicone-coated glass without $(S G)$ and with $\left(S G^{+}\right)$a salivary coating

The value of the relative local density, $g(\theta)$, is given for selected angular sections between $-90^{\circ}$ and $90^{\circ}$ with respect to the direction of flow. A relative local density equal to unity is denoted ' 0 ', whereas deviations up to $10 \%$ are denoted ' + ' (or ' - ') and deviations larger than $10 \%$ are indicated as ' ++ ' (or ' -- '). These experiments were done in low ionic strength buffer.

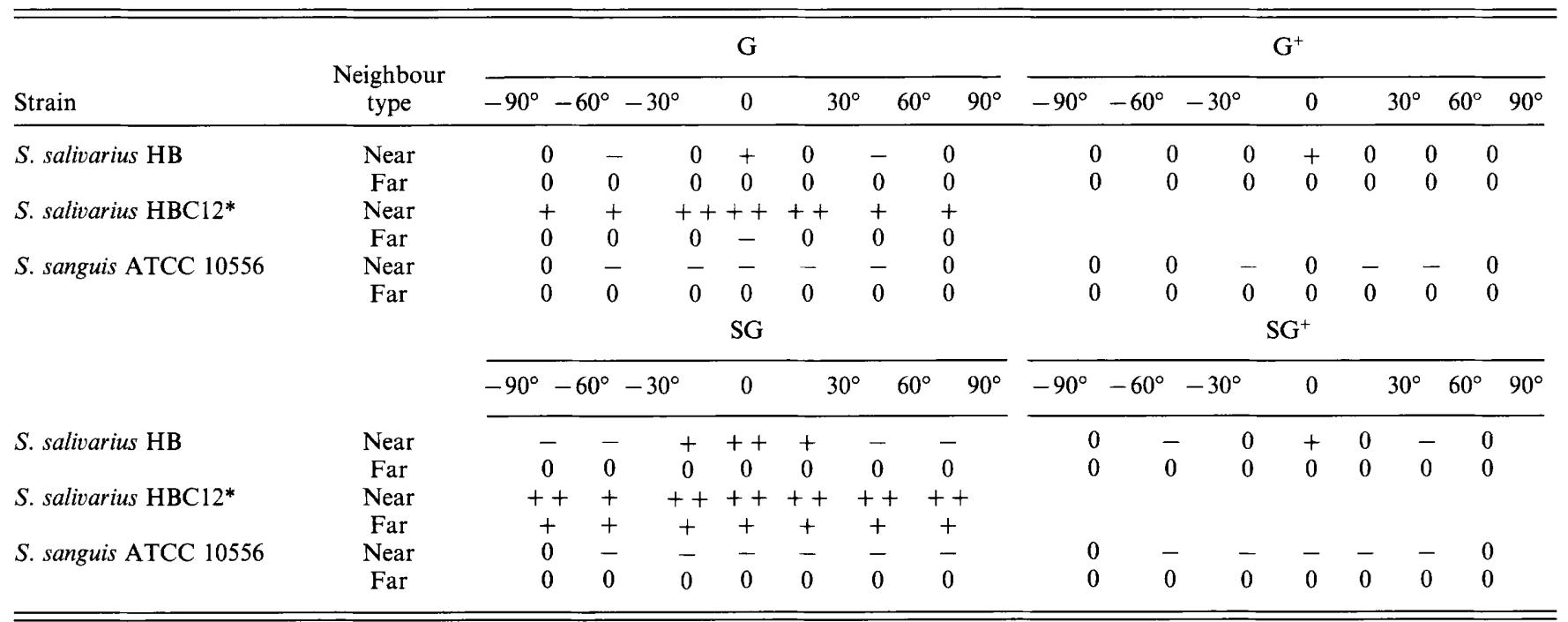

* The number of $S$. salivarius $\mathrm{HBC1} 2$ cells on the saliva-coated substrata was too small in the field of view to enable calculation of distribution functions.

$1 \cdot 1$ (for S. sanguis ATCC 10556 on the hydrophobic substratum), indicative of the absence of positive cooperativity, to 1.7 (for $S$. salivarius $\mathrm{HBC12}$ on the hydrophobic substratum), a value that may be considered representative of positive cooperativity.

The angular distribution functions (Table 6) demonstrate that any influence of the direction of flow upon the deposition process has disappeared for the far neighbours, except for $S$. salivarius $\mathrm{HBCl} 2$ on the hydrophobic substratum. However, for near neighbours a preference as well as an aversion for deposition in the direction of flow can exist.
Amino acid analysis and gel electrophoresis of adsorbed salivary films

Each surface was able to bind salivary proteins as shown by the presence of amino acids in hydrolysates of pellicle material (Table 7). Each pellicle yielded a unique amino acid profile, showing selectivity in terms of buffer and surface. SDS-PAGE also yielded unique patterns of protein binding (Fig. 5). The glass surface yielded a large amount of a $75 \mathrm{kDa}$ protein, whereas this protein was present in only relatively small amounts on siliconecoated glass. Note from Table 7 that the differences in 
Table 7. Amino acid analyses of salivary pellicles on glass $(G)$ or silicone-coated glass $(S G)$

Values are given in mol amino acid (mol alanine) $)^{-1}$. The composition of buffers 1 and 2 is given in Table 2. ND, Not detectable.

\begin{tabular}{lccccc}
\hline \hline Amino acid & Saliva (control) & G (buffer 1) & SG (buffer 1) & G (buffer 2) & SG (buffer 2) \\
\hline Asp & 1.03 & 0.72 & 0.12 & 1.09 & $1 \cdot 10$ \\
Glu & 1.60 & 3.84 & 0.31 & 3.28 & 1.99 \\
Ser & 0.85 & 1.70 & 0.15 & 1.16 & 1.82 \\
Gly & 1.24 & 3.89 & 0.27 & 2.38 & 2.88 \\
His & 0.18 & 4.07 & 0.05 & 0.70 & 0.54 \\
Arg & 0.73 & 3.62 & 0.10 & 1.02 & 1.03 \\
Thr & 0.77 & 0.70 & 0.08 & 0.83 & 0.98 \\
Ala & 1.00 & 1.00 & 1.00 & 1.00 & 1.00 \\
Pro & 0.87 & 5.93 & 0.37 & 3.20 & 3.90 \\
Tyr & 0.23 & 0.68 & 0.06 & 0.23 & 0.66 \\
Val & 0.65 & 0.38 & 0.09 & 0.62 & 0.98 \\
Met & 0.03 & 0.06 & ND & 0.11 & 0.16 \\
Cystine & 0.42 & 0.26 & 0.25 & ND & 2.39 \\
Ile & 0.40 & 0.21 & 0.07 & 0.43 & 0.66 \\
Leu & 0.71 & 0.46 & 0.09 & 0.73 & 0.94 \\
Phe & 0.36 & 0.65 & 0.06 & 0.35 & 0.58 \\
Lys & 0.48 & 2.03 & 0.06 & 0.82 & 0.66 \\
\hline \hline
\end{tabular}

amino acid composition between the two substrata are much more pronounced in low ionic strength buffer (buffer 1) than in high ionic strength buffer (buffer 2).

\section{Discussion}

Positive cooperativity is a mechanism proposed for the adhesion of certain bacteria to surfaces. The purpose of this study was to attempt a critical evaluation of two methods that claim to assess experimentally cooperative phenomena, namely Scatchard analysis and the analysis of the spatial arrangement of adhering cells. Since the latter type of analysis has to be based on flow chamber adhesion experiments, these experiments also yielded extensive data on the kinetics of adhesion of the strains to various substrata. These data must first be considered prior to discussing the cooperative phenomena observed.

\section{Kinetics of adhesion}

The kinetics of adhesion can best be studied in a flow chamber system as this yields the most detailed information. Therefore no kinetic experiments have been done using vials. However, previous experiments with vials have shown that a stationary state is reached within $1 \mathrm{~h}$ (Cowan et al., 1986). Differences in mass transport conditions between the flow chamber and the vial experiment preclude a comparison of the kinetics in both systems. When considering the initial deposition rates of the various strains to the different substrata in the flow chamber experiments there appear to be only small differences for $S$. salivarius $\mathrm{HB}$ and $S$. sanguis ATCC
10556 when comparing the effects of a salivary coating. However, the deposition of $S$. salivarius $\mathrm{HBC} 12$ to glass was significantly lower (Student's $t$-test, $P<0 \cdot 1$ ) than to silicone-coated glass. Possibly, this was due to the presence of interfacial water on this extremely hydrophilic bald strain (Table 1 and Fig. 1) and on the hydrophilic glass, discouraging successful deposition. Obviously, removal of interfacial water from hydrophobic silicone-coated glass will be easier, thereby facilitating successful deposition. The differences in zeta potentials among this collection of strains is small ( -7 to $-13 \mathrm{mV}$ ) and probably cannot be held accountable for any significant differences in electrostatic repulsion influencing deposition. It is noted that the deposition rates measured are all relatively high compared to a theoretical deposition rate, $j_{0}^{*}$, which can be calculated from the Smoluchowski-Levich equation (Adamczyk \& Van de Ven, 1981). For the present experimental conditions, $j_{0}^{*}$ equals $440 \mathrm{~cm}^{-2} \mathrm{~s}^{-1}$. As this is significantly lower than the experimentally observed value, we can conclude either that sedimentation greatly contributes to the mass transport and/or that additional attractive electrostatic interactions exist between heterogeneously charged domains on the interacting surfaces.

Since the reciprocal adhesion time constants (Table 3) show major differences for the various strain/substrata combinations, the numbers of cells adhering in the stationary state also show great differences and no relation exists between $j_{0}$ and $n_{\mathrm{s}}$. The adhesion of $S$. salivarius $\mathrm{HBC} 12$ is clearly lowest, whereas $S$. sanguis ATCC 10556 adheres in lower numbers to hydrophobized glass than to bare glass (Student's $t$-test, 


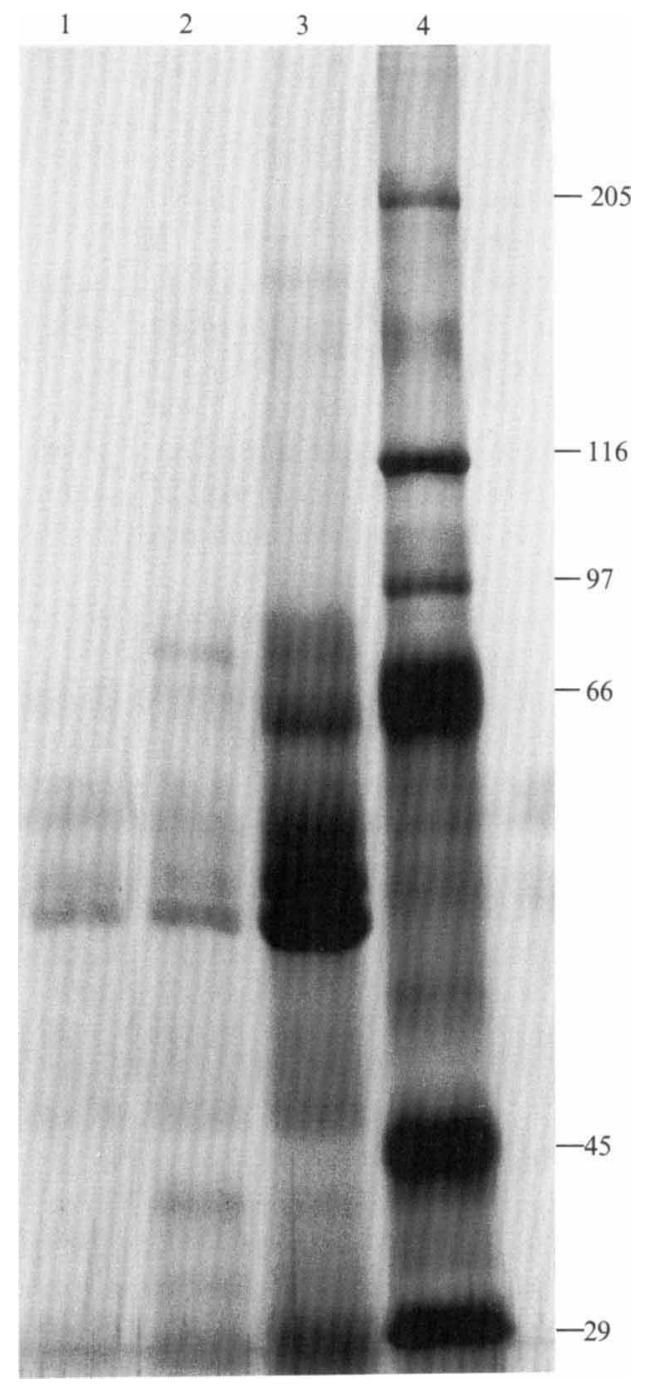

Fig. 5. SDS-PAGE of acquired pellicle. Lanes: 1, silicone-coated glass; 2, glass; 3, saliva; 4, protein standards (negotin, $205 \mathrm{kDa} ; \beta$ galactosidase, $116 \mathrm{kDa}$; phosphorylase $\mathrm{B}, 97 \mathrm{kDa}$; bovine serum albumin, $66 \mathrm{kDa}$; ovalbumin, $45 \mathrm{kDa}$; and carbonic anhydrase, $29 \mathrm{kDa}$ )

$P<0.05)$ in accordance with thermodynamics, i.e. the most hydrophobic strain (Table 1) adheres best to the hydrophobized glass. S. sanguis ATCC 10556 also exhibits different numbers of adhering cells to salivacoated glass than to saliva-coated silicone-coated glass, suggesting that a different type of salivary film has adsorbed on these substrata as previously observed by Rykke \& Rölla (1990) on hydrophilic and hydrophobic substrata. $S$. salivarius HB shows hardly any differences in numbers of adhering cells for both hydrophilic and hydrophobic substrata with or without a salivary coating.

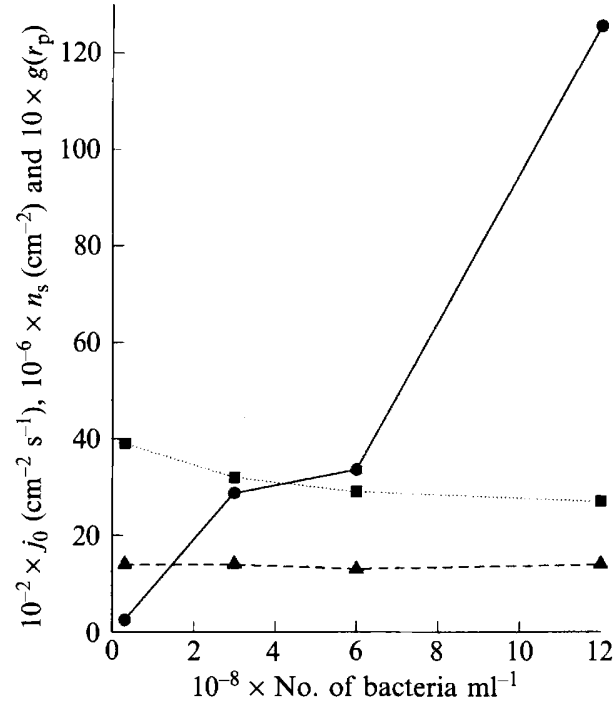

Fig. 6. Initial deposition rates, $j_{0}(\bullet)$, numbers of cells adhering in the stationary state, $n_{\mathrm{s}}(\boldsymbol{\square})$, and relative local density, $g\left(r_{\mathrm{p}}\right)(\mathbf{\Delta})$, for $S$ salivarius HB to glass in low ionic strength buffer as a function of cell density in suspension. Data represent single run experiments.

All strains show distinct two-phase adhesion kinetics as evidenced by the higher reversibility after $1000 \mathrm{~s}$ as compared to after $5000 \mathrm{~s}$ (Table 4). Such two-phase kinetics in streptococcal adhesion have also been described by Busscher et al. (1986) and Cowan et al. (1986). The reversibility of adhesion for $S$. salivarius $\mathrm{HBC} 12$ is an order of magnitude higher than for the other strains, a factor which might be attributed to the presence of tightly bound interfacial water on its cell surface, removal of which is essential to create practically irreversible bonding. The high reversibility of $S$. salivarius $\mathrm{HBC12}$ adhesion to bare substrata is in correspondence with the high percentages of cells removed by draining the flow chamber. At this stage it must be emphasized however, that removal of cells adhering to a salivary film by draining occurs not necessarily through failure at the cell/film interface but in the majority of cases, most likely through cohesive failure in the adsorbed protein film (Busscher et al., 1992). The slightly higher reversibility on bare substrata of $S$. salivarius $\mathrm{HB}$ in comparison with $S$. sanguis ATCC 10556 could be due to the more negative zeta potential of strain HB (Table 1), which results in a higher repulsive force between the interacting surfaces.

In a separate experiment we determined the dependence of $j_{0}$ and $n_{\mathrm{s}}$ (Fig. 6) on the bacterial cell densities in suspension for $S$. salivarius $\mathrm{HB}$ to glass only. Whereas $n_{\mathrm{s}}$ did not vary with cell density, $j_{0}$ increased linearly with cell density in agreement with mass transport theories (Sjollema et al., 1988). From the fact that $n_{\mathrm{s}}$ hardly varied with cell density, it may be concluded that the reversibility of adhesion as expressed 

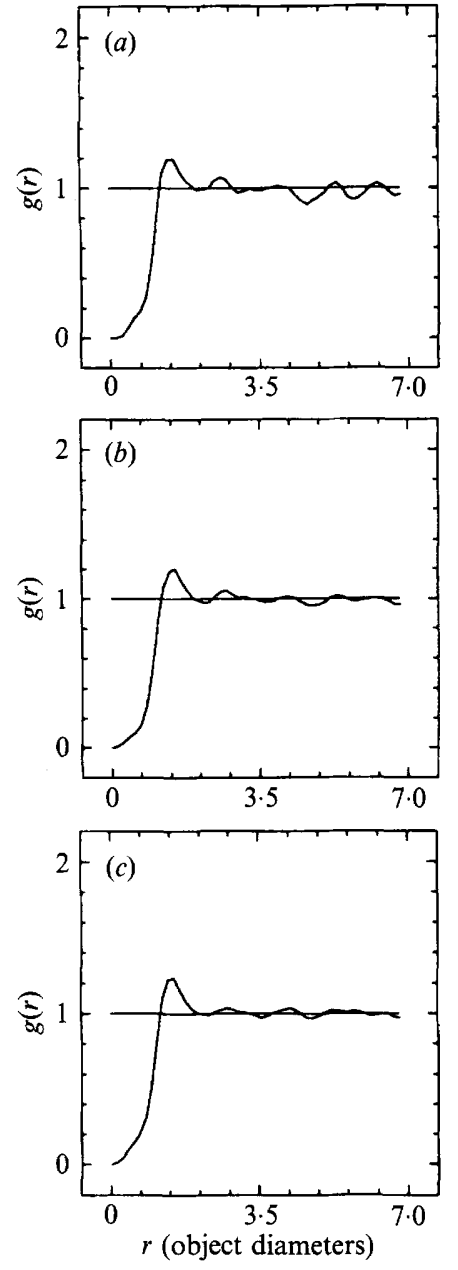

Fig. 7. Radial distribution functions of $S$. salivarius HB (in low ionic strength buffer) to glass, taken after (a) 1.5 , (b) 2.5 and (c) $3.5 \mathrm{~h}$ in the same experiment representing different degrees of surface coverage by the adhering cells.

by $\alpha$ must be considered as relatively low, although of course reversibility is a process that must be considered in relation to its time dependence, i.e. even in the case of low reversibility, all cells may desorb after an infinitely long time interval.

\section{Analysis of the spatial arrangement of adhering cells to assess cooperative phenomena}

The collection of near neighbours by adhering microorganisms is a direct corollary of positive cooperativity. In addition, distribution functions as calculated in this paper, yield quantitative data on the details of the spatial arrangement of adhering cells without any assumptions, including the blocking distance, the distance of preferential adhesion and the degree of preferential adhesion. Also, in the case of flow, the effect of flow on the spatial arrangement can be visualized. However, a flow chamber device for such observations is required and a minimal number of adhering cells has to be present to allow this type of analysis, which is the reason why for $S$. salivarius $\mathrm{HBC} 12$ on saliva-coated substrata, analysis of the spatial arrangement was impossible in this study.

At first glance it might be expected that the distribution functions would be dependent on the number of adhering bacteria $\mathrm{cm}^{-2}$. Such an expectation is not justified however, since we are dealing with a chance process and the likelihood of a cell to deposit far away or close to an adhering cell, is in principle not affected by the number of adhering cells. To further illustrate this point, we have calculated radial distribution functions $1.5,2.5$ and $3.5 \mathrm{~h}$ after the onset of the deposition of $S$. salivarius $\mathrm{HB}$ to glass, corresponding with the presence of $9 \times 10^{6}, 14 \times 10^{6}$ and $20 \times 10^{6}$ cells $\mathrm{cm}^{-2}$, respectively. Within statistical limitations, it can be seen that the three distribution functions shown in Fig. 7 are identical. On those occasions when we did encounter different distribution functions at different degrees of surface coverage, the analysis usually contained too small a number of particles.

The observations on the present collection of strains and substrata do not show a more pronounced degree of near-neighbour collection on hydrophobic substrata than on hydrophilic substrata as observed previously (Busscher et al., 1990). Also, whereas we have suggested previously that surface appendages, as on $S$. salivarius HB (Fig. 1), are required for cells to adhere by means of positive cooperativity (Sjollema, et al., 1990a,b), this conclusion could not be confirmed by the present study. There are some important differences in experimental conditions between the studies of Busscher et al. (1990) and Sjollema et al. $(1990 a, b)$ that may account for these discrepancies involving the shear rate applied and the type of buffer and its ionic strength. S. salivarius $\mathrm{HBC12}$, a completely bald strain (Fig. 1), shows a high degree of near-neighbour collection, despite its lack of surface appendages. The $S$. salivarius $\mathrm{HBC} 12$ cells however, though adhering, appeared not to be immobilized and could glide more or less over the surface. Probably, for this strain, incomplete immobilization is the source for a high degree of near-neighbour collection.

It is a matter of choice to determine how large $g\left(r_{\mathrm{p}}\right)$ should be before one can talk about positive cooperativity. Previously, for inert polystyrene particles $g\left(r_{\mathrm{p}}\right)$ values ranging from 1.2 to 1.4 were reported (Sjollema \& Busscher, 1990), which might provide a criterion for the absence of positive cooperativity. It has also been suggested that to decide whether the cooperative phenomena are present, one should consider the angular distribution functions. For inert polystyrene particles (Sjollema \& Busscher, 1990) it has invariably been found that particles preferred not to adhere in the 
Table 8. A comparison of the mechanisms of non-cooperative $(N C)$ or cooperative $(C)$ adhesion of the three oral streptococcal strains used with regard to their adhesion to glass without $(G)$ and with $\left(G^{+}\right)$ a salivary coating, and to silicone-coated glass without $(S G)$ and with $\left(S G^{+}\right)$a salivary coating as revealed by Scatchard analyses of adhesion data, and analysis of the spatial arrangement of adhering cells

Corresponding results of both types of analysis for a given strain/substratum combination are indicated by boxes. Note that the degree of cooperativity, i.e. $g\left(r_{\mathrm{p}}\right)$ for the distribution function analysis is given in parentheses. Only the data of adhesion experiments done in low ionic strength buffer are compared.

\begin{tabular}{|c|c|c|c|c|c|c|c|c|c|}
\hline Strain & Method & G & & $\mathrm{G}^{+}$ & & SG & & $\mathrm{SG}^{+}$ & \\
\hline S. salivarius $\mathrm{HB}$ & $\begin{array}{l}\text { Scatchard } \\
\text { Distribution functions }\end{array}$ & $\begin{array}{r}\mathrm{NC} \\
\mathrm{C}\end{array}$ & $(1 \cdot 3)$ & $\mathrm{C}$ & $(1 \cdot 3)$ & $\begin{array}{l}\mathrm{C} \\
\mathrm{C}\end{array}$ & $(1 \cdot 3)$ & $\begin{array}{l}\mathrm{C} \\
\mathrm{C}\end{array}$ & $(1 \cdot 3)$ \\
\hline S. salivarius $\mathrm{HBC} 12$ & $\begin{array}{l}\text { Scatchard } \\
\text { Distribution functions }\end{array}$ & $\begin{array}{r}\mathrm{NC} \\
\mathrm{C}\end{array}$ & $(1 \cdot 5)$ & NC & & $\begin{array}{r}\mathrm{NC} \\
\mathrm{C}\end{array}$ & $(1 \cdot 7)$ & NC & \\
\hline S. sanguis ATCC 10556 & $\begin{array}{l}\text { Scatchard } \\
\text { Distribution functions }\end{array}$ & $\begin{array}{l}\mathrm{NC} \\
\mathrm{NC}\end{array}$ & $(1 \cdot 2)$ & $\mathrm{C}$ & $(1 \cdot 4)$ & $\begin{array}{r}\mathrm{C} \\
\mathrm{NC}\end{array}$ & $(1 \cdot 1)$ & $\begin{array}{l}\mathrm{NC} \\
\mathrm{NC}\end{array}$ & $(1 \cdot 2)$ \\
\hline
\end{tabular}

*-indicates that the number of $S$. salivarius $\mathrm{HBC12}$ cells in the field of view was too small to enable calculations of distribution function.

direction of flow. This type of behaviour could also be explained on the basis of hydrodynamic and colloid chemical theory (Dabros, 1989). Only for microorganisms adhering by cooperative mechanisms has a distinct preference for cells to adhere in the direction of flow been observed (Table 6). Thus, it is proposed that any decisive conclusion concerning whether or not cells exhibit positive cooperativity should be based on both the radial and the angular distribution functions.

\section{Positive cooperativity from Scatchard analysis}

The main advantage of this technique to assess positive cooperativity is that it is easily and quickly done, but the assumptions for the justified application of the Scatchard equation are not all met. To our knowledge, adhesion data for neither $S$. salivarius HB nor HBC12 have yet been subjected to Scatchard analysis. S. sanguis ATCC 10556 has been shown previously to adhere by means of positive cooperative mechanisms to saliva-coated hydroxylapatite beads (Nesbitt et al., 1982), which was also found in this study for its adhesion to saliva-coated glass.

Amino acid analysis and gel electrophoresis of adsorbed protein salivary film

There are a number of observations in this study indicating that a different salivary film develops on a hydrophobic substratum than on a hydrophilic substratum: $j_{0}, n_{\mathrm{s}}$ and $g\left(r_{\mathrm{p}}\right)$ of $S$. sanguis ATCC 10556 are different on saliva-coated glass as compared to salivacoated silicone-coated glass. Scatchard analysis shows $S$. salivarius $\mathrm{HB}$ to exhibit positive cooperativity on salivary films on glass and silicone-coated glass, whereas for $S$. sanguis ATCC 10556 positive cooperativity was only found on the saliva-coated glass in low ionic strength buffer. The amino acid analysis and gel electrophoresis of salivary films performed here confirm the findings by Rykke \& Rölla (1990) that substrata with different hydrophobicities collect different salivary films (Table 7), although in an absolute sense our amino acid analysis yields different results, most likely due to the use of pooled saliva in this study and differences in solubilization methods.

Attempts were made to correlate acquired pellicle amino acid composition with adhesion patterns. Calculations of hydrophobic residues or hydrophilic residues to alanine (as an arbitrary standard) did not yield a value which would be predictive in terms of cooperative adhesion. Furthermore, the electrophoretic profiles of acquired film proteins were not predictive with respect to adhesion patterns. It may be that small amounts of a particular protein could greatly influence adhesion. The present experimental design was not directed to fractionating saliva for individual adhesins. Nevertheless, the results clearly show that a particular buffer and a particular surface binds a unique set of proteins.

\section{Derivation and mechanisms of positive cooperativity}

In Table 8 the conclusions are summarized with regard to the mechanisms of adhesion of the three strains to different substrata derived from the Scatchard analysis of adhesion data and from an analysis of the spatial arrangement of adhering cells. For $S$. salivarius HB both methods yielded contradictory conclusions when bare glass was the substratum, but corresponding ones for silicone-coated glass and the saliva-coated substrata. 
Possibly the requirements necessary to successfully apply Scatchard analysis are better fulfilled on a more hydrophobic substratum than on the hydrophilic substratum, glass. Particularly, it is noted that the reversibility factor of adhesion, $\alpha$, is $2-5$ times higher on the hydrophobized glass than on hydrophilic glass (Table 4). Both methods yield dissimilar conclusions for $S$. salivarius $\mathrm{HBC} 12$ on the bare substrata, despite the fact that this strain adheres the most reversibly of all strains involved. S. salivarius $\mathrm{HBC12}$, however, appeared to be very poorly immobilized by adhesion which suggests that sliding of adhering cells may cause the high degree of near-neighbour collection in the flow chamber experiments. Thus, it must be concluded that near neighbour collection need not necessarily be a corollary of positive cooperativity but that it may also be a result of incomplete immobilization of adhering cells. For $S$. sanguis ATCC 10556, both methods yielded similar adhesion mechanisms in three of the four cases, the exception being silicone-coated glass.

The present study shows that positive cooperativity not only occurs on protein-coated substrata but also on inert materials. Therefore, the original statement of Doyle et al. (1982) that positive cooperativity involved the creation of new receptor sites through conformational changes of adsorbed proteins by initially bound cells has to be extended. Possibly on inert substrata, bound cells may excrete biopolymers adsorbing to the substratum, thereby making the microenvironment of the cell more favourable for subsequent adhesion. Alternatively, suspended cells may be attracted more towards an adhering cell than to other suspended cells which would also yield positive cooperativity.

This work was supported by grants of the Netherlands Organization for Scientific Research (NWO), NIH-NIDR DE-07199 and the North Atlantic Treaty Organization (NATO). The authors are greatly indebted to Mrs Marjon Schakenraad-Dolfing and Mrs Ellen van Drooge for manuscript preparation. Dr J. Singh was helpful in the amino acid analyses and the PAGE experiments.

\section{References}

AdAMCZyK, Z. \& VAN DE Ven, T. G. M. (1981). Deposition of particles under external forces in laminar flow through parallel plate and cylindrical channels. Journal of Colloid and Interface Science 80, 340-356.

Busscher, H. J., Uyen, M. H. W. J. C., Van Pelt, A. W. J., WEERKAMP, A. H. \& ARENDS, J. (1986). Kinetics of adhesion of the oral bacterium Streptococcus sanguis $\mathrm{CH} 3$ to polymers with different surface free energies. Applied Environmental Microbiology 51, 910-914.

Busscher, H. J., SJollema, J. \& VAN Der Mei, H. C. (1990). Relative importance of surface free energy as a measure of hydrophobicity in bacterial adhesion to solid surfaces. In Microbial Cell Surface
Hydrophobicity, pp. 335-359. Edited by R. J. Doyle \& M. Rosenberg. Washington, DC: American Society for Microbiology. Busscher, H. J., Cowan, M. M. \& VAN Der MeI, H. C. (1992). On the relative importance of specific and non-specific approaches to oral microbial adhesion. FEMS Microbiology Reviews 88, 199-210.

Cowan, M. M., TAYlor, K. G. \& Doyle, R. J. (1986). Kinetic analysis of Streptococcus sanguis adhesion to artificial pellicle. Journal of Dental Research 65, 1278-1283.

DABRos, T. (1989). Interparticle hydrodynamic interactions in deposition processes. Colloids and Surfaces 39, 127-141.

DABRos, T. \& VAN DE VEN, T. G. M. (1982). Kinetics of coating by colloid particles. Journal of Colloid and Interface Science 89, 232-244.

Dawes, C., Watanabe, S., Biglow-Lecomte, P. \& Dibdin, G. H. (1989). Estimation of the velocity of the salivary film at some different locations in the mouth. Journal of Dental Research 68 , $1479-1482$.

DoyLE, R. J. (1991). Strategies in experimental microbial adhesion research. In Microbial Cell Surface Analysis-Structural and Physicochemical Methods, pp. 291-316. Edited by N. Mozes, P. S. Handley, H. J. Busscher \& P. G. Rouxhet. New York: VCH Publishers Inc.

Doyle, R. J., Nesbitt, W. E. \& Taylor, K. G. (1982). On the mechanism of adhesion of Streptococcus sanguis to hydroxylapatite. FEMS Microbiology Letters 15, 1-5.

JAMES, A. M. (1991). Charge properties of microbial cell surfaces. In Microbial Cell Surface Analysis-Structural and Physicochemical Methods, pp. 221-262. Edited by N. Mozes, P. S. Handley, H. J. Busscher \& P. G. Rouxhet. New York: VCH Publishers Inc.

LAEMmLI, U. K. (1970). Cleavage of structural proteins during the assembly of the head of bacteriophage $\mathrm{T}_{4}$. Nature, London 227 , 680-685.

Nesbitt, W. E., Doyle, R. J., TAylor, K. G., StaAt, R. H. \& Arnold, R. R. (1982). Positive cooperativity in the binding of Streptococcus sanguis to hydroxylapatite. Infection and Immunity 35, 157-165.

Pratt-Terpstra, I. H., Weerkamp, A. H. \& Busscher, H. J. (1987). Adhesion of oral streptococci from a flowing suspension to uncoated and albumin-coated surfaces. Journal of General Microbiology 133, 3199-3206.

RYKKE, M. \& Rölla, G. (1990). Effect of silicone oil on protein adsorption to hydroxyapatite in vitro and on pellicle formation in vivo. Scandinavian Journal of Dental Research 98, 401-411.

Sjollema, J. \& Busscher, H. J. (1990). Deposition of polystyrene particles in a parallel plate flow cell. 2. Pair distribution functions between deposited particles. Colloids and Surfaces 47, 337-352.

SJollema, J., Busscher, H. J. \& WeERKAMP, A. H. (1988). Deposition of oral streptococci and polystyrene particles onto glass in a parallel plate flow cell. Biofouling 1, 101-112.

Suollema, J., Van der Mei, H. C., Uyen, H. M. W. \& Busscher, H. J. (1990a). The influence of collector and bacterial cell surface properties on the deposition of oral streptococci in a parallel plate flow cell. Journal of Adhesion Science Technology 4, 765-777.

Sjollema, J., Van der Mei, H. C., Uyen, H. M. \& Busscher, H. J. $(1990 \mathrm{~b})$. Direct observation of cooperative effects in oral streptococcal adherence to glass by analysis of the spatial arrangement of adhering bacteria. FEMS Microbiology Letters 69 , 263-267.

Tweedie, D. J., Fernandez, D., Spearman, M. E., Feldhoff, R. C. \& Prough, R. A. (1991). Metabolism of azoxy derivatives of procarbazine by aldehyde dehydrogenase and xanthine oxidase. Drug Metabolism and Disposition 19, 793-803.

VAN DeR Mei, H. C., Rosenberg, M. \& Busscher, H. J. (1991). Assessment of microbial cell surface hydrophobicity. In Microbial Cell Surface Analysis - Structural and Physicochemical Methods, pp. 263-287. Edited by N. Mozes, P. S. Handley, H. J. Busscher \& P. G. Rouxhet. New York: VCH Publishers Inc.

Vissink, A., Waterman, H. A., 's-Gravenmade, E. J., Panders, A. K. \& VERMEY, A. (1984). Rheological properties of saliva substitutes containing mucin, carboxymethylcellulose or polyethylenoxide. Journal of Oral Pathology 13, 22-28. 